UDC 347.66

LBC 67.304 .8

\title{
THE RIGHT TO ASPARIGINASE OF THE TESTATOR: THE SEARCH FOR BALANCE OF INTERESTS
}

\author{
Aleksandr V. Fedchun \\ Institute of law and entrepreneurship, Saint Petersburg, Russian Federation
}

\begin{abstract}
Introduction: the article is devoted to problems related to the adoption of inheritance, assessment of hereditary weight and the possibilities of challenging transactions of the testator not only the heirs but also of creditors. For this purpose, the author analyzes the issues related to the existence of the right to contest of transactions of the deceased, as his heirs, and the creditors of the testator, is not a party to the transaction. Methods: applied in conjunction methods of scientific knowledge, including basic methods of system analysis and comparative-legal. Results: the author analyzes the schema inheritance relationships, it is established that at this stage there are two inheritance relationships - from the fact of opening of the inheritance and succession, stages of succession, the questions connected with the possibility of increasing value of estates due to the invalidation of transactions concluded by the testator during his life, and the use of restitution. Conclusions: the author proposes to give the creditors of the testator, is not a party to the transaction, the right to challenge transaction and the right to demand the application of consequences of invalidity of such transactions in the absence of the hereditary property, sufficient to meet the claims of creditors in full volume and with appropriate legal grounds for invalidation of a transaction outside the bankruptcy process.
\end{abstract}

Key words: the creditor of the testator, the contesting of the transactions of the testator, the return of property to the estate.

УДК 347.66

ББК 67.304 .8

\section{ПРАВО НА ОСПАРИВАНИЕ СДЕЛОК НАСЛЕДОДАТЕЛЯ: ПОИСК БАЛАНСА ИНТЕРЕСОВ}

\author{
Александр Витальевич Федчун \\ Институт правоведения и предпринимательства, г. Санкт-Петербург, Российская Федерация
}

\begin{abstract}
Введение: статья посвящена выявлению проблем, связанных с принятием наследства, оценкой наследственной массы и возможностям оспаривания сделок наследодателя не только наследниками, но и кредиторами. С этой целью автор анализирует вопросы, связанные с наличием права на оспаривание сделок наследодателя, как у его наследников, так и у кредиторов наследодателя, не являющихся стороной в сделке. Методы: применены в совокупности методы научного познания, среди которых основные - методы системности, анализа и сравнительно-правовой. Результаты: автором проанализированы схемы наследственных правоотношений, установлено, что на этом этапе наследования возникают два правоотношения - из факта открытия наследства и по принятию наследства, выделены этапы наследования, исследован вопрос, связанный с возможностью увеличения стоимости наследственной массы за счет признания недействительными сделок, заключенных

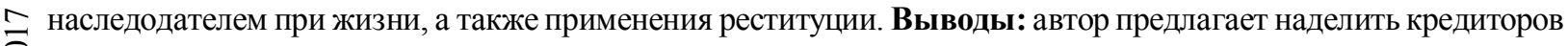
글 наследодателя, не являющихся стороной в сделке, правом на ее оспаривание, а также правом требовать примеضे нения последствий недействительности подобной сделки в случае отсутствия наследственного имущества, д достаточного для удовлетворения требований кредиторов в полном объеме, а также при наличии соответствующих правовых оснований для признания сделки недействительной вне процедуры банкротства.

Ключевые слова: кредитор наследодателя, оспаривание сделок наследодателя, возврат имущества в состав наследства.
\end{abstract}


Введение. При жизни физические лица, участвуя в гражданском обороте, заключают сделки и могут оставлять наследникам после своей смерти не только имущество, но и долги перед кредиторами. Наследники сталкиваются с ситуацией, связанной с необходимостью объективной оценки стоимости наследственной массы на стадии принятия наследства, чтобы уяснить для себя, стоит ли предпринимать какие-либо активные действия в связи с принятием наследства и погашением долгов наследодателя, поскольку размер этих долгов может превышать стоимость наследуемого имущества. Бывает, что наследодатель вступает в сделки, которые влекут изъятие значительной части имущества из наследственной массы. В таких случаях наследники имеют право инициировать обращение в суд с целью оспаривания сделок, которые были заключены при жизни наследодателем. Кредиторы наследодателя в таких ситуациях значительно ограничены в правах на защиту своих имущественных интересов.

Такие случаи являются предметом исследования автора настоящей статьи. Значительный интерес представляет анализ вопросов, связанных с наличием права на оспаривание сделок наследодателя как у его наследников, так и у кредиторов наследодателя, не являющихся стороной в сделке.

Наследники являются субъектами наследственного правоотношения. Не столь однозначен ответ на вопрос о том, являются ли кредиторы наследодателя участниками наследственного правоотношения. Для определения субъектного состава участников наследственного правоотношения необходимо дать правовую характеристику таким правоотношениям.

Содержание понятия наследственного правоотношения уже много лет является предметом исследования многих цивилистов. Например, Б.С. Антимонов и К.А. Граве полагали, что при наследовании существуют два правоотношения: первое возникает из события, то есть открытия наследства, а второе в связи с принятием наследства по воле наследника [1, с. 26]. Большинство авторов предлагают делить наследственные правоотношения на две стадии (виды). О.С. Иоффе исходил из того, что наследственные право- отношения проходят две стадии: «На первой стадии у наследника существует единственное правомочие на принятие наследства, которое является по своей правовой природе абсолютным. На второй стадии наследственное правоотношение сохраняется в качестве правового основания тех прав (право собственности, обязательственные и иные права), которые принадлежали наследодателю. На второй стадии наследственное правоотношение также предопределяет объем прав и обязанностей по отношению к конкретным лицам (кредиторам и должникам наследодателя), которые становятся кредиторами и должниками наследника. При этом сохраняется наследственное правоотношение в своем абсолютном качестве, поскольку против притязаний третьих лиц, оспаривающих правомочия наследника на принятие наследства, наследник может защищаться со ссылкой на наследственное правоотношение в качестве основания возникновения своих имущественных прав» [5, с. 290]. А.В. Трапезникова пишет, что «данная позиция неверна только потому, что в последнем случае (то есть на второй стадии - прим. автора) наследник перестает быть таковым, становясь обычным кредитором - управомоченной стороной не наследственного, а обязательственного правоотношения. Если же речь идет о принятии наследства в виде вещей, то он (наследник) становится собственником, то есть активной стороной в вещном правоотношении» [14].

В современной отечественной цивилистической науке наиболее подробно о схеме развития наследственных правоотношений пишет Н.С. Кириллова [6, с. 56].

По мнению автора, на этом этапе наследования возникают два правоотношения - из факта открытия наследства и по принятию наследства, первое из которых носит абсолютный характер, существует не более шести месяцев и прекращается возникновением правоотношений по принятию наследства или отказу от него. Правоотношение по принятию наследства (отказа от наследства) Н.С. Кириллова считает односторонней сделкой, порождающей юридические права и обязанности, и, следовательно, являющейся самостоятельным правоотношением. Она поддерживает точку зрения О.С. Иоффе относительно 
существования двух стадий наследственного правоотношения.

Первый этап, как уже было отмечено, начинается с момента смерти наследодателя и заканчивается моментом принятия наследства (отказа от наследства). Второй этап наследования начинается с момента принятия наследства наследниками и заканчивается моментом определения правовой судьбы наследственного имущества. Именно на этом этапе возникают правоотношения, связанные с погашением долгов наследодателя, разделом наследственного имущества, исполнением завещания, наследственным отказом, возложением обязанностей по охране и доверительному управлению наследством и т. д.

В процессе наследования наследники вступают в правоотношения не только между собой, но и с иными лицами, указанными в законе (нотариус, отказополучатели, кредиторы наследодателя и иные лица).

Л.И. Корчевская указывает, что наследственное правоотношение - это комплекс гражданско-правовых отношений, которые возникают с открытием наследства. К их числу следует отнести правоотношения из факта принятия наследства: по принятию наследства, отказу от наследства, по исполнению завещания, из наследственного отказа, из возложения, наследственной трансмиссии, субституции, в связи с подназначением наследников, по приращению наследственных долей, а также правоотношения кредиторов по поводу наследственного имущества [7, с. 56]. Исходя из такого широкого понимания наследственного правоотношения, можно предполагать, что кредиторы наследодателя также являются участниками наследственного правоотношения как на первой стадии (до момента принятия наследства (отказа от наследства) наследниками), так и на второй стадии наследственного правоотношения. На первой стадии кредитору приходится иметь дело с юридической фикцией, призванной на этапе принятия наследства заполнить те «пустоты», которые впоследствии займут наследники, и именуемой «наследственная масса».

В соответствии со ст. 1175 ГК РФ каждый из наследников отвечает по долгам наследодателя в пределах стоимости перешедшего к нему наследственного имущества.
Кредиторы наследодателя вправе предъявить свои требования к принявшим наследство наследникам в пределах сроков исковой давности, установленных для соответствующих требований. До принятия наследства требования кредиторов могут быть предъявлены к исполнителю завещания или к наследственному имуществу.

Согласно ст. 1112 ГК РФ и господствующей в доктрине точки зрения, входящие в состав наследства права и обязанности переходят от наследодателя к наследникам в порядке универсального правопреемства как единое целое и «одномоментно», за исключением тех прав и обязанностей, наследование которых не допускается в силу ГК и других законов либо противоречит самой природе этих прав и обязанностей [12, с. 9-14]. Между тем ряд российских цивилистов полагают, что долги, обременяющие наследство, не являются составной частью наследства, а лишь обременяют его. Так, Н.Д. Егоров писал, что при наследовании речь должна идти не о правопреемстве, а о преемстве, причем не в самих правах, а в объектах этих прав [13, с. $30-$ 31]. Данная точка зрения является весьма спорной. Автору ближе позиция Д.И. Мейера, который писал, что «...большей частью обязательственные отношения могут сохранять силу и после смерти их первого участника, и только некоторые из них по необходимости прекращаются после смерти лица, например, личный найм, доверенность. Таким образом, для законодательства представляется необходимость определить судьбу юридических отношений, переживающих своего субъекта, установить, кто вправе вступить в эти отношения. И вот это-то и составляет право наследования» [8, с. 779-780].

Обязанность доказывать долги наследодателя возложена на кредитора (ст. 1175 ГК РФ). В то же время ГК РФ не возлагает на участников наследственных правоотношений обязанности выявлять состав долгов наследодателя, устанавливать его кредиторов, извещать их об открытии наследства.

Поскольку кредиторы наследодателя могут удовлетворить свои требования только из стоимости наследственной массы, весьма актуален вопрос, связанный с возможностью увеличить ее стоимость за счет признания 
недействительными сделок, заключенных наследодателем при жизни, а также применения реституции.

Следует заметить, что право на оспаривание таких сделок позволяет защитить интересы не только кредиторов наследодателя, но и его наследников. Последние также заинтересованы в увеличении объема перешедшего к ним наследства.

Проблема перехода права на оспаривание сделок к наследникам в порядке универсального правопреемства затрагивалась учеными-цивилистами разных стран с момента появления в научной литературе термина «секундарные права». Э. Зеккель еще в начале $\mathrm{XX}$ в. писал о существовании правомочий особого рода. Суть данных преобразовательных правомочий заключается в возможности своими собственными действиями создавать, изменять или прекращать правовые возможности иных лиц. В российской правовой доктрине эти правомочия именуются «секундарными правами» [4, с. 205-252; 15, с. 253-270].

В отечественной литературе высказывались различные позиции относительно возможности перехода по наследству права на оспаривание сделок наследодателя.

Так, О.В. Гутников и В.А. Белов приводили различные аргументы в пользу того, что право на оспаривание не может переходить к наследникам в порядке универсального правопреемства [2, с. 205-207; 10, с. 1350-1367].

Э. Зеккель, Я.Э. Розенфельд, А.А. Ягельницкий придерживаются противоположной точки зрения [11, с. 180; 18, с. 76-106].

Правоприменительная практика судов общей юрисдикции уже достаточно давно признавала возможность оспаривания сделок наследниками [9].

В настоящее время согласно п. 73 Постановления Пленума Верховного суда РФ № 9 от 29.05.2012 г. «О судебной практике по делам о наследовании» наследники вправе обратиться в суд после смерти наследодателя с иском о признании недействительной совершенной им сделки, в том числе по основаниям, предусмотренным ст. 177, 178 и 179 ГК РФ, если наследодатель эту сделку при жизни не оспаривал, что не влечет изменения сроков исковой давности, а также порядка их исчисления.
Вопрос о начале течения срока исковой давности по требованиям об оспоримости сделки разрешается судом на основании конкретных обстоятельств дела (например, обстоятельств, касающихся прекращения насилия или угрозы, под влиянием которых наследодателем была совершена сделка) и с учетом того, когда наследодатель узнал или должен был узнать об обстоятельствах, являющихся основанием для признания сделки недействительной.

Таким образом, высшая судебная инстанция восприняла правовую позицию сторонников концепции, предполагающей возможность универсального наследственного правопреемства права на оспаривание сделок, заключенных наследодателем. Следует только приветствовать такой подход в решении данного вопроса.

Каков круг наследников, управомоченных на оспаривание сделки? Если наследник один, то ответ на вопрос очевиден. Если же наследников несколько, то право на оспаривание, равно как и одобрение оспоримой сделки может быть реализовано ими только совместно. В случае раздела наследства, а также при составлении завещания, в котором наследодатель определяет правовую судьбу своего имущества (в том числе имущественных прав, вытекающих из сделок), необходимо уяснить, могут ли правомочия на оспаривание и одобрение оспоримой сделки быть выделены в качестве самостоятельных имущественных правомочий и переданы одному из наследников отдельно от остальных правомочий (например, права требования; обязанности передать имущество, выплатить денежные средства и т. д.), вытекающих из сделок.

А.А. Ягельницкий не исключает такой возможности [18]. Полагаем, что эта позиция не может быть поддержана, поскольку право на оспаривание сделки предполагает наличие имущественного интереса стороны сделки, связанной, например, с необходимостью передачи (возврата) имущества. Реституция, применяемая при признании оспоримой сделки недействительной, направлена на восстановление имущественной сферы каждой из сторон сделки в первоначальное положение и на защиту интересов добросовестных участников гражданского оборота. 
При возникновении ситуации, когда один из наследников получит право на оспаривание (одобрение) сделки, а другой - право требования из оспоримой сделки, возникает «несогласованность» действий наследников в рамках сделки, заключенной наследодателем. Ведь обладатель права требования по сделке может быть вовсе не заинтересован в ее оспаривании, и своими действиями, связанными с фактическим принятием исполнения по сделке, одобрить ее совершение. В то же время правовой интерес в оспаривании сделки наследником - обладателем соответствующего права на оспаривание может быть иным. Такое поведение наследников может поставить в тупик контрагента по сделке с наследодателем, интересы которого также необходимо учитывать в данном случае.

Полагаем, что право на оспаривание сделки, возникающее у наследника, не должно «расщепляться» и существовать отдельно от иных его прав и обязанностей, вытекающих из заключенной наследодателем при жизни сделки и перешедших в порядке универсального наследственного правопреемства наследнику. В настоящее время наиболее остро стоит проблема, связанная с возможностью оспаривания сделок наследодателя его кредиторами, которые не участвуют в подобных сделках в качестве ее стороны.

Правоприменительная практика в ходе оспаривания сделок наследодателя его кредиторами выявила комплекс проблем, требующих выработки подходов для их решения. К сожалению, ни действующее законодательство, ни судебная практика до сих пор не дали ответы на многие вопросы, возникающие в данной сфере общественных отношений.

Как известно, российское законодательство (ст. 166 ГК РФ) исходит из классического понимания порочности сделки. Сделки являются недействительными ipso iure независимо от признания их таковыми судом (ничтожные сделки) либо ope exceptionis, то есть в силу принятия судом возражения, препятствующего исполнению сделки (оспоримые сделки). Ничтожные сделки обладают свойством абсолютности, что предполагает возможность сделать заявление в суде о недействительности ничтожной сделки любым заинтересованным лицом. Д.О. Тузов предложил именовать такой иск негационным (от лат. «negation»-«отрицание») [16, с. 9].

Оспоримые сделки имеют свойство относительности, поэтому право на признание такой сделки недействительной имеет строго определенный круг лиц. Подобное деление недействительных сделок на ничтожные и оспоримые вполне объяснимо, поскольку в первом случае дефект сделки связан с нарушением общего интереса, а во втором - с нарушением охраняемого законом интереса определенного ограниченного круга лиц, который управомочен выразить свою волю для аннулирования сделки.

В ныне действующей редакции п. 2 ст. 166 ГК РФ указано, что право на предъявление требования о признании оспоримой сделки недействительной принадлежит ее стороне. Иные лица могут оспорить такую сделку только в случаях, предусмотренных законом.

В силу п. 3 ст. 166 ГК РФ требование о признании недействительной ничтожной сделки может быть удовлетворено, если лицо, предъявляющее такое требование, имеет охраняемый законом интерес в признании этой сделки недействительной. Таким образом, круг лиц, управомоченных заявлять в суде требование о признании недействительной ничтожной сделки, достаточно широк и не ограничен сторонами сделки, а также лицами, указанными в законе. Достаточно доказать факт наличия охраняемого законом интереса в признании подобной сделки недействительной.

Между тем для лиц, оспаривающих сделку, важно не только признать ее недействительной, но и получить возможность применить реституцию. Изменения, внесенные в ст. 166 ГК РФ, ограничивают круг лиц, наделенный такой возможностью. Ранее требование о применении последствий ничтожной сделки могло заявить любое заинтересованное лицо.

Д.О. Тузов отмечал, что предоставление такого права лицам, которые не участвуют в сделке, противоречит назначению реституции, которая является по своей правовой природе частноправовым притязанием [17, с. 207-210]. Полагаем возможным не согласиться с автором в отношении таких субъектов, как кредиторы наследодателя. Кредитор наследодате- 
ля может требовать признания в данном случае недействительной ничтожной сделки. Его имущественный интерес очевиден, поскольку сделка может быть направлена на отчуждение имущества наследодателя, что уменьшает стоимость наследственной массы и снижает возможности кредитора вернуть имеющуюся у наследодателя перед кредитором задолженность. Для обоснования такого имущественного интереса достаточно предоставить соответствующие подтверждающие документы о наличии задолженности, если в отношении таковой отсутствует спор о праве. В противном случае кредитор должен подтвердить в судебном порядке наличие долга.

В то же время констатация того факта, что сделка является ничтожной, не позволяет кредитору по собственной инициативе требовать применения последствий недействительности сделки и вернуть имущество в состав наследства.

Кредиторы наследодателя вправе оспорить сделку, применив реституцию в рамках процедуры банкротства наследственной массы, предусмотренной Федеральным законом от 26.10.2002 г. № 127-Ф3 «О несостоятельности (банкротстве)» (ст. 213.32, 223.1). Однако не все так просто.

Правом на оспаривание обладает финансовый управляющий по своей инициативе либо по решению собрания кредиторов или комитета кредиторов, а также конкурсный кредитор или уполномоченный орган, если размер его задолженности, включенный в реестр требований, превышает $10 \%$ общего размера кредиторской задолженности, включенной в реестр (не считая размера требований кредитора, в отношении которого сделка оспаривается, и его заинтересованных лиц). Таким образом, далеко не каждый кредитор вправе оспорить сделку в рамках процедуры банкротства наследственной массы.

Действующее законодательство о банкротстве устанавливает критерии, которые позволяют оспорить сделку наследодателя. В соответствии со ст. 61.1 закона № 127-Ф3 фактически признать недействительной оспоримую сделку, а также применить последствия недействительности сделок в рамках процедуры банкротства кредиторы, не являющие- ся стороной сделки, могут в большинстве случаев только по основаниям, предусмотренным главой III.1 закона № 127-ФЗ. Кредитор наследодателя, не являющийся стороной сделки, лишен возможности оспорить большинство сделок и применить последствия их недействительности на основании положений параграфа 2 главы 9 ГК РФ.

Немаловажную роль в данной ситуации имеет то обстоятельство, что процедура банкротства требует дополнительных финансовых затрат, связанных с выплатой вознаграждения финансовому управляющему. Подобного рода расходы могут быть компенсированы только за счет наследственной массы, что может значительно уменьшить шансы кредитора вернуть долг.

Кредитор, который обращается в суд с целью банкротства наследственной массы, должен дополнительно, помимо установленного законом перечня документов, предоставить доказательства неплатежеспособности должника (наследодателя), то есть его неспособности удовлетворить в полном объеме требования кредиторов по денежным обязательствам. Если не доказано иное, наследодатель предполагается неплатежеспособным при условии, что имеется хотя бы одно из обстоятельств, указанных в п. 3 ст. 213.6 закона № 127-Ф3.

Все вышеперечисленные обстоятельства позволяют сделать вывод о том, что имущественные интересы кредиторов наследодателя не получают должной защиты. Создается дисбаланс интересов и нездоровая почва для различного рода злоупотреблений, в том числе со стороны наследников, не заинтересованных в оспаривании сделок по тем или иным причинам (например, заключение договора займа, по которому наследодатель передал близкому родственнику наследника денежные средства под влиянием угроз последнего (ст. 179 ГК РФ)).

Каковы критерии, определяющие недобросовестный характер поведения наследодателя и позволяющие оспорить сделку? Должны ли в данной ситуации ущемляться имущественные интересы добросовестных контрагентов наследодателя по сделкам?

Никто не знает время наступления своей смерти, и потому нельзя полагаться на 
A.B. Федчун. Право на оспаривание сделок наследодателя: поиск баланса интересов

дату смерти в качестве одного из критериев оценки сделки на предмет порочности. В данном случае правильнее говорить о неплатежеспособности наследодателя, которая может быть установлена как при его жизни, так и после смерти в ходе выявления кредиторской задолженности наследодателя.

Основные подходы для определения критериев оспаривания подобного рода сделок, а также условий и порядка такого оспаривания уже сформулированы в главе III.1 Федерального закона от 26.10.2002 г. № 127-Ф3 «О несостоятельности (банкротстве)». Кредиторы при этом не должны лишаться возможности использовать в качестве оснований для оспаривания сделок предусмотренные параграфом 2 главы 9 ГК РФ правовые нормы, а также требовать применения последствий недействительности сделок, оспоренных по таким основаниям.

Полагаем, что закон должен наделять кредиторов наследодателя, не являющихся стороной в сделке, правом на ее оспаривание, а также правом требовать применения последствий недействительности подобной сделки в случае отсутствия наследственного имущества, достаточного для удовлетворения требований кредиторов в полном объеме, а также при наличии соответствующих правовых оснований для признания сделки недействительной вне процедуры банкротства. Такого рода нововведение в действующее гражданское законодательство является необходимым исключением из правила, устанавливающего жесткие «ограничители» по кругу лиц для оспаривания сделок и применения последствий признания их недействительными. Вполне логичным представляется дополнить ст. 1175 ГК РФ частью 4, в которой будет закреплено право кредиторов оспаривать сделки наследодателя.

Такой подход позволит обеспечить баланс интересов между участниками сделки и кредиторами наследодателя, не являющимися стороной сделки. Возможность активного участия кредиторов наследодателя в процессе оспаривания сделок позволит вернуть имущество в состав наследства, что благотворным образом скажется на защите имущественных интересов добросовестных наследников.

\section{СПИСОК ЛИТЕРАТУРЫ}

1. Антимонов, Б. С. Советское наследственное право / Б. С. Антимонов, К. А. Граве. - М. : Юрид. лит., 1955. - 26 с.

2. Гутников, О. В. Недействительные сделки в гражданском праве. Теория и практика оспаривания / О. В. Гутников. - М. : Бератор-Пресс, 2003. C. 205-207.

3. Егоров, Н. Д. Гражданско-правовое регулирование общественных отношений: единство и дифференциация / Н. Д. Егоров. - Л. : Изд-во Ленингр. ун-та, 1988. - С. 166-169.

4. Зеккель, Э. Секундарные права в гражданском праве / Э. Зеккель // Вестник гражданского права. - 2007. - № 2. - С. 205-252.

5. Иоффе, О. С. Советское гражданское право. Курс лекций. Ч. 3 / О. С. Иоффе. - Л. : Изд-во Ленингр. ун-та, 1965. - 290 с.

6. Кириллова, Н. С. Наследственное правоотношение : дис. ... канд. юрид. наук / Кириллова Надежда Станиславовна. - М. : Юрид. ин-т МВД России, 2002. -207 с.

7. Корчевская, Л. И. Объекты наследственного преемства в условиях экономических преобразований : дис. ... канд. юрид. наук / Корчевская Любовь Ивановна. - М., 1997. - 245 с.

8. Мейер, Д. И. Русское гражданское право / Д. И. Мейер. - М. : Статут, 2000. - 831 с.

9. Определение Верховного суда РФ от 16.05.2006 № 5-В06-25. - Доступ из справ.-правовой системы «КонсультантПлюс».

10. Практика применения Гражданского кодекса РФ, частей второй и третьей / под общ. ред. В. А. Белова. - М. : Юрайт, 2009. - 1161 с.

11. Розенфельд, Я. Э. Оспоримые сделки : дис. ... канд. юрид. наук / Я. Э. Розенфельд. - М. : МГУ им. М. В. Ломоносова, 1979. - 180 с.

12. Сергеев, А. П. Комментарий к Гражданскому кодексу Российской Федерации (постатейный). Ч. 3 / А. П. Сергеев, Ю. К. Толстой, И. В. Елисеев. М. : Проспект, 2002. - С. 9-14.

13. Серебровский, В. И. Очерки советского наследственного права / В. И. Серебровский. - М. : Изд-во АН СССР, 1953. - 237 с.

14. Трапезникова, А. В. Наследственное правоотношение: концепция и суть / А. В. Трапезникова // Наследственноеправо. - 2012. - № 4. - С. 22-25. - Доступ из справ.-правовой системы «КонсультантПлюс».

15. Третьяков, С. В. Формирование концепции секундарных прав в германской цивилистической доктрине (к публикации русского перевода Э. Зеккеля «Секундарные права в гражданском праве») / С. В. Третьяков // Вестник гражданского права. 2007. - № 2. - С. 253-270. - Доступ из справ.-правовой системы «КонсультантПлюс». 
16. Тузов, Д. О. Иски, связанные с недействительностью сделок. Теоретический очерк / Д. О. Тузов ; под ред. Б. Л. Хаскельберг, В. М. Чернов. Томск : Пеленг, 1998. - 72 с.

17. Тузов, Д. О. Реституция при недействительности сделок и защита добросовестного приобретателя в российском гражданском праве / Д. О. Тузов. - М. : Статут, 2007. - С. 207-210.

18. Ягельницкий, А. А. Наследственное преемство в праве на оспаривание сделки» / А. А. Ягельницкий // Вестник гражданского права. - 2010. № 5. - С. 76-106. - Доступ из справ.-правовой системы «КонсультантПлюс».

\section{REFERENCES}

1. Antimonov B.S., Grave K.A. Sovetskoe nasledstvennoe pravo [Soviet Succession Law]. Moscow, Yurid. lit. Publ., 1955. 26 p.

2. Gutnikov O.V. Nedeystvitelnye sdelki v grazhdanskom prave. Teoriya $i$ praktika osparivaniya [Invalid Transactions in Civil Law. Theory and Practice of Contestation]. Moscow, Berator-Press, 2003, pp. 205-207.

3. Egorov N.D. Grazhdansko-pravovoe regulirovanie obshchestvennykh otnosheniy: edinstvo i differentsiatsiya [Civil-Law Regulation of Public Relations: Unity and Differentiation]. Leningrad, Izd-vo Leningr. un-ta, 1988, pp. 166-169.

4. Zekkel E. Sekundarnye prava v grazhdanskom prave [Secondary Rights in the Civil Law]. Vestnik grazhdanskogo prava, 2007, no. 2, pp. 205-252.

5. Ioffe O.S. Sovetskoe grazhdanskoe pravo. Kurs lektsiy. Ch. 3 [The Soviet Civil Law. A Course of Lectures. Part 3]. Leningrad, Izd-vo Leningr. un-ta, 1965. 290 p.

6. Kirillova N.S. Nasledstvennoe pravootnoshenie: dis. ... kand. yurid. nauk [Succession Legal Relations. Cand. jurid. sci. diss.]. Moscow, Yurid. in-t MVD Rossii, 2002. 207 p.

7. Korchevskaya L.I. Obyekty nasledstvennogo preemstva $v$ usloviyakh ekonomicheskikh preobrazovaniy: dis. ... kand. yurid. nauk [The Objects of the Hereditary Succession in the Conditions of Economic Transformations. Cand. jurid. sci. diss.]. Moscow, 1997. $245 \mathrm{p}$.

8. Meyer D.I. Russkoe grazhdanskoe pravo [Russian Civil Law]. Moscow, Statut Publ., 2000. 831 p.
9. Opredelenie Verkhovnogo suda RF ot 16.05.2006 № 5-V06-25 [Definition of the Supreme Court of the Russian Federation of May 16, 2006 no. 5V06-25]. Access from Reference Legal System "KonsultantPlyus".

10. Belov V.A., ed. Praktika primeneniya Grazhdanskogo kodeksa RF, chastey vtoroy i tretyey [Practice of Application of the Civil Code of the Russian Federation, Parts Two and Three]. Moscow, Yurayt Publ., 2009. 1161 p.

11. Rozenfeld Ya.E. Osporimye sdelki: dis. ... kand. yurid. nauk [Voidable Transactions. Cand. jurid. sci. diss.]. Moscow, MGU im. M. V. Lomonosova, 1979. $180 \mathrm{p}$.

12. Sergeev A.P., Tolstoy Yu.K., Eliseev I.V. Kommentariy k Grazhdanskomu kodeksu Rossiyskoy Federatsii (postateynyy). Ch. 3 [Comment to the Civil code of the Russian Federation (itemized). Part Three]. Moscow, Prospekt Publ., 2002, pp. 9-14.

13. Serebrovskiy V.I. Ocherki sovetskogo nasledstvennogo prava [Essays of the Soviet Succession Law]. Moscow, Izd-vo AN SSSR, 1953. $237 \mathrm{p}$.

14. Trapeznikova A.V. Nasledstvennoe pravootnoshenie: kontseptsiya i sut [Succession Legal Relations: Concept and Essence]. Nasledstvennoe pravo, 2012, no. 4, pp. 22-25.

15. Tretyakov S.V. Formirovanie kontseptsii sekundarnykh prav v germanskoy tsivilisticheskoy doktrine (k publikatsii russkogo perevoda E. Zekkelya «Sekundarnye prava v grazhdanskom prave») [The Formation of the Concept of Secondary Rights in German Civil Doctrine (to the Publication of the Russian Translation of E. Zekkel Secondary Rights in the Civil Law)]. Vestnik grazhdanskogo prava, 2007, no. 2, pp. 253-270.

16. Tuzov D.O. Iski, svyazannye snedeystvitelnostyu sdelok. Teoreticheskiy ocherk [The Claims Related to Invalidity of Transactions. Theoretical Essay]. Tomsk, Peleng Publ., 1998. 72 p.

17. Tuzov D.O. Restitutsiya pri nedeystvitelnosti sdelok $i$ zashchita dobrosovestnogo priobretatelya v rossiyskom grazhdanskom prave [Restitution at the Invalidity of Transactions and the Protection of Bona Fide Purchaser in the Russian Civil Law]. Moscow, Statut Publ., 2007, pp. 207-210.

18. Yagelnitskiy A.A. Nasledstvennoe preemstvo $\mathrm{v}$ prave na osparivanie sdelki [Hereditary Succession in the Right to Claim the Transaction]. Vestnik grazhdanskogo prava, 2010, no. 5, pp. 76-106. 


\section{Information about the Author}

Aleksandr V. Fedchun, Candidate of Juridical Sciences, Associate Professor, Department of Civil Law and Civil Procedure, Institute of law and entrepreneurship, Malaya St., 8, 196601 Saint Petersburg, Russian Federation, 9705393@mail.ru.

\section{Информация об авторе}

Александр Витальевич Федчун, кандидат юридических наук, доцент кафедры гражданского права и гражданского процесса, Институт правоведения и предпринимательства, ул. Малая, 8, 196601 г. Санкт-Петербург, Российская Федерация, 9705393@mail.ru. 